\title{
A emergência do subesquema [V_que] na rede dos conectores condicionais
}

DOl: http://dx.doi.org/10.21165/el.v50i2.3038

\section{Camila Gabriele da Cruz Clemente'}

\section{Resumo}

O objetivo principal é descrever os processos de mudança que levaram à emergência do subesquema [V_que] na rede dos conectores condicionais no português. Os dados foram coletados do Corpus do Português, disponível em www.corpusdoportugues.org, e do BITProhpor, disponível em https://www.prohpor.org/bit-banco-pb, datados nos séculos XVIII a XX. A base teórica deste trabalho vincula-se aos modelos baseados no uso, sobretudo, a Traugott e Trousdale (2013) e pelos estudos acerca da condicionalidade de Dancygier (1998) e Oliveira (2019a, 2019b). A princípio, embora o subesquema [V_que] apresente baixa produtividade, observa-se que a cada século ela aumenta, conforme mostram os dados coletados. Como resultado, observou-se que esse subesquema emerge na rede dos conectores condicionais da língua portuguesa com o surgimento das microconstruções "supondo que", por processo de construcionalização, a partir da mudança do verbo "supor" para a forma gerúndio "supondo" + a conjunção "que", e de "dado que" e "posto que", por mudanças construcionais, uma vez que essas microconstruções apresentavam, antes do século XIX, apenas significado causal.

Palavras-chave: construcionalização; mudança construcional; condicionalidade.

1 Universidade Federal de São Carlos (UFSCar), São Carlos, São Paulo, Brasil; camila.clemente@estudante.ufscar.br; https://orcid.org/0000-0003-0709-6888 


\title{
The emergence of the subschema [V_que] in the conditional connectors network
}

\begin{abstract}
This paper describes the change processes that led to the emergence of the subschema [V_que] as a conditional connector in Portuguese. Data were collected from Corpus do Português, on www.corpusdoportugues.org, and from BlT-Prohpor, on https://www. prohpor.org/bit-banco-pb, dated from 18th to 20th centuries. This paper follows after the Usage-Based approach, essentially Traugott and Trousdale's (2013) theory of change and Dancygier's (1998), and Oliveira's (2019a, 2019b) studies about conditionality. Although the subschema [V_que] presents low productivity, it is observed that every century it increases, as shown by the data collected. As a result, it was observed that the emergence of this subschema in the conditional connectors network of the Portuguese language is due to the constructionalization of the micro-construction "supondo que" (that was a verb "supor" and it has changed for gerund "supondo" + the conjunction "que") and also due to the constructional changes of the micro-constructions "dado que" and "posto que" (which were just micro-constructions from the causal network before the 19th century).
\end{abstract}

Keywords: constructionalization; construction change; conditionality.

\section{Introdução}

Ao abordar a emergência do conector "supondo que" na rede condicional, Oliveira (2019a) propõe o subesquema [V_que], composto da combinação "verbo + conjunção que", que sanciona as microconstruções "dado que", "posto que", "supondo que", entre outras. Nas ocorrências, a seguir, é possível observar o valor condicional de algumas microconstruções do subesquema [V_que] em uso:

1. Então eu iria pra casa - ia dar uma - vistoria na geladeira pra ver o que que tinha lá e supondo que tivesse - carne né? faria - bife - com batatas porque sei que com certeza vocês iriam adorar batatas fritas (190r:Br:LF:SP_-CdP)

2. Assim acontecera a S. Diogo, que estuprara uma donzela e, saciada a fome bestial, lançara o corpo a um rio. E, posto que aquele grande criminoso fosse beatificado e da vítima nem se soubesse o nome, grande mercê seria para todo o cristão ser-lhe poupado tal cálice. Eu assim implorava, e tão encarecido e exaustivo foi meu rogo que adormeci extenuado. (19:Fic:Pt:Ribeiro:Avia- CdP). 
3. Não sabia responder isto e até hoje não sei responder, e ainda mais se me perguntava, nesse caso de alcoólico: no ato da geração, dado que fosse a verdade essa sinistra teoria da herança de defeitos e vícios, o pai já seria deveras um alcoólico que tivesse as suas células fecundantes suficientemente modificadas, igualmente, para transmitir a sua desgraça ao filho virtual? (19:Fic:Br:Barreto:Cemitério- CdP).

As ocorrências de (1) a (3) são compostas pelas microconstruções fundadoras do subesquema condicional [ $\left.\mathrm{V}_{-} q u e\right]$, escolhidas como recorte nesse trabalho para compreender a emergência desse subesquema.

Em trabalhos anteriores, as microconstruções do subesquema [V_que] já haviam sido estudadas separadamente, como em Hirata-Vale (2012) e Oliveira (2019a), que analisaram o conector "supondo que", e Cavaguti e Hirata-Vale (2014), sobre o "dado que". Há também trabalhos que citam o subesquema condicional [V_que], tais como os de Oliveira (2019a, 2019b). Entretanto, nenhum desses trabalhos contempla, especificamente, o processo de emergência do subesquema condicional [V_que] na língua portuguesa. Em função disso, o objetivo desse artigo é descrever as mudanças que levaram à emergência desse subesquema na rede dos conectores condicionais, pelo viés da teoria da mudança linguística, de base construcional, de Traugott e Trousdale (2013).

Eainda, também se pretendeverificar qualé o grau de pertencimento das microconstruções do subesquema [V_que] na categoria condicional, já que tal fato revela a gradiência na definição de categoriais, questão bastante apontada pelos modelos baseados no uso. Sendo assim, as microconstruções serão analisadas, conforme alguns parâmetros de Dancygier (1998), para verificar qual é a contribuição de cada membro para a criação do sentido condicional.

Em relação à estrutura, este artigo se organiza da seguinte maneira: o suporte teórico, que trata os conceitos relevantes da teoria de Traugott e Trousdale (2013) para a análise, tais como, visão de língua, construção, construcionalização e mudança construcional. Logo após, encontra-se a definição das construções condicionais. Na seção seguinte, apresenta-se a metodologia, com informações sobre o corpus e as características dos dados coletados. Na sequência, a análise dos dados, com base nos parâmetros apresentados na descrição da metodologia. Por fim, as considerações finais sobre a emergência do subesquema condicional [V_que] na língua portuguesa.

\section{Suporte teórico: a teoria da mudança de Traugott e Trousdale (2013)}

A teoria proposta por Traugott e Trousdale (2013) para tratar da mudança linguística se enquadra em um conjunto de modelos teórico-metodológicos nominados como Modelos Baseados no Uso (LANGACKER, 1987). Como diz o próprio nome, os modelos baseados no uso defendem que a gramática da língua é moldada pelas pressões do uso de seus 
usuários. Assim, estudiosos como Traugott e Trousdale (2013) dão muita importância ao contexto discursivo e defendem a necessidade de análise de dados reais, de língua em uso.

Em linhas gerais, Traugott e Trousdale (2013) defendem a visão de língua enquanto um sistema organizado em redes de construções interligadas, susceptível a mudanças. Tudo na língua são construções, desde morfemas e afixos a estruturas complexas, como as expressões idiomáticas, tratadas como pareamentos de forma e significado, por Traugott e Trousdale (2013, p. 8, tradução nossa):

$$
[[F] \leftrightarrow[S]]
$$

F é a abreviação para a forma e S para o significado. As setas demonstram o pareamento de forma e significado, que estão entre colchetes, convencionalizados como uma única construção. Segundo Croft (2001, p. 18), a forma compreende propriedades sintáticas, morfológicas e fonológicas, enquanto o significado corresponde a propriedades semânticas, pragmáticas e discursivo-funcionais. No caso do subesquema [V_que], por exemplo, propõe-se o seguinte esquema geral para representá-lo como construção:

$$
\left[\left[\left[V_{-} q u e\right]_{\text {con }} \text { ORAÇÃO } O_{x} \text { ORAÇÃO }\right] \leftrightarrow[\text { [ CONDICIONA y }]\right]
$$

No esquema acima "con" refere-se à atuação de conector da construção [V_que], uma vez que essa é utilizada para conectar duas orações, a oração x e a oração y. As setas representam a multidirecionalidade de forma e significado (forma: [[V_que $]_{\text {con }}$ ORAÇÃO ORAÇÃO,]; significado: [x CONDICIONA y]). O significado corresponde à forma [V_que] em uso, isto é, seu significado na língua, de unir duas orações, $x$ e y, em uma relação de condição.

Traugott e Trousdale (2013) argumentam que as construções costumam seguir os seguintes passos de mudança linguística:

$1^{\circ}$ Inovação: o ouvinte interpreta uma construção e o analisa de uma maneira não correspondente à do falante (há uma neoanálise). Mais tardiamente, esse ouvinte torna-se o enunciador e reutiliza o construto com o novo sentido, mas ainda não convencionalizado.

$2^{\circ}$ Convencionalização: outro ouvinte passa a utilizar o construto com o novo sentido.

$3^{\circ}$ Construcionalização: quando a neoanálise morfossintática e semântica são compartilhadas na comunidade de falantes, cria-se, então, uma nova microconstrução na rede. 
$4^{0}$ Pós-construcionalização: pode haver a expansão da nova microconstrução e essa reorganizar-se em subesquemas.

$5^{0}$ Redução de forma: o uso frequente da construção pode levar à redução da forma ou sua diminuição de uso pode levar à sua obsolescência.

A partir daí, é possível notar que o uso linguístico é o gatilho para o processo da mudança, que ocorre de maneira gradual, em micropassos. Os significados são negociados na interação verbal devido às necessidades dos usuários da língua e, assim, ocorrem as mudanças linguísticas.

Langacker (1982) argumenta que compreender a língua também implica compreender os processos externos a ela, tais como, a parte da mente humana responsável pela visão, pelas habilidades musicais etc. Isso porque o usuário da língua consegue criar novos links e nós por meio de associações cognitivas, por processos metafóricos e/ou análogos de neoanálise.

Os usuários da língua criam novas construções a partir de sequências já existentes na língua ou similares a elas. Mais especificamente, Traugott e Trousdale (2013) apontam que novas construções podem surgir devido a mudanças construcionais, ou seja, alterações em uma das subpartes de construções já existentes, ou na forma ou no significado, o que não acarreta um novo símbolo. Como exemplificação, toma-se a mudança nos subcomponentes da construção "will", do inglês, descrita por Traugott e Trousdale (2013, p. 1): no nível semântico, mudou de "ter a intenção" para "expressão de futuro"; no nível sintático, passou de verbo pleno para verbo auxiliar; no nível morfofonológico, pode reduzir-se a 'll e aglutinar-se a pronomes pessoais.

Há ainda outro processo por meio do qual as redes linguísticas podem sofrer mudanças, denominado por construcionalização, em que se criam novos pareamentos de forma e significado. Como exemplo, tem-se o caso de "a gente", fruto da combinação de duas construções que possuíam formas e significados diferentes: artigo "a" + substantivo "gente", no português brasileiro, que quando utilizada como "a gente" em alguns contextos, possui o significado de construção pronominal de primeira pessoa, segundo Soares (2014).

No geral, a abordagem construcional de Traugott e Trousdale (2013) apresenta os seguintes postulados básicos:

i. A língua é um sistema adaptativo complexo, organizado em redes de construções interligadas; 
ii. As construções são as unidades básicas da língua, compostas pelo pareamento de forma e significado;

iii. As construções podem variar em graus de esquematicidade, produtividade e composicionalidade;

iv. Mudanças construcionais ocorrem constantemente na língua. Caracterizam-se pela alteração em apenas uma das partes da construção - ou da forma ou do significado e podem ocorrer antes e após o processo de construcionalização;

v. Construcionalização ocorre quando há alterações em ambas as partes da construção, o que acarreta uma nova construção na rede.

Além disso, na teoria de Traugott e Trousdale (2013) existem três postulados fundamentais para a análise das construções. São eles: esquematicidade, produtividade e composicionalidade. Esquematicidade refere-se à posição hierárquica da construção na rede, ou ainda, ao preenchimento de seu slot. Quanto mais esquemática uma construção, mais possibilidades de preenchimento de slot ela possui. O subesquema [V_ que] condicional, por exemplo, encontra-se em nível intermediário de esquematicidade até o século XX. Uma vez que sanciona construções menos esquemáticas, no nível de microconstruções, a construção [V_que] encontra-se no nível de subesquema e pode ser parcialmente preenchida, a parte $\vee$, pois a parte "que" já possui forma fixa.

Produtividade está atrelada aos conceitos de frequência type, frequência de tipo, e token, frequência de ocorrências. Neste trabalho, por exemplo, toma-se como objeto de pesquisa o subesquema condicional [V_que] e, para representá-lo, as coletas de dados são feitas na busca pelos três types inaugurais - "dado que", "posto que" e "supondo que". Atualmente, o subesquema [V_que] sanciona mais types, e se mostra altamente produtivo, mas não é o foco deste artigo. No total, o subesquema condicional [V_que] apresenta 37 tokens até o século XX. Sendo assim, apresenta baixa produtividade type e baixa produtividade token até o século XX.

Composicionalidade é medida pela relação de transparência entre forma e significado. Em outras palavras, uma construção é mais composicional quanto mais a soma de suas partes constitui seu significado. Geralmente, no processo de mudança linguística, as construções se tornam menos composicionais, uma vez que sofrem alterações em suas características semânticas e/ou sintáticas. Nesse artigo, defende-se que as construções condicionais são não composicionais, "já que não resulta da simples soma do significado das partes que compõem a estrutura condicional." (OLIVEIRA, 2019b, p. 119). Nas seções seguintes será possível perceber que vários elementos trabalham em conjunto para garantir o significado condicional nas construções compostas pelas microconstruções do subesquema [V_que]. 
Partindo dos pressupostos até aqui explicitados, esse trabalho pretende descrever como surgiu o subesquema [V_que] na rede dos conectores condicionais. Na próxima seção, apresentam-se algumas noções gerais acerca das construções condicionais.

\section{As construções condicionais}

As construções condicionais apresentam, tradicionalmente, a estrutura sintática "se p, q" (DANCYGIER, 1998), na qual p corresponde à construção condicionante e q, à construção condicionada. Veja:

4. [Supondo que metade deste número étirado dos importados depois do tráfico] [construção condicionante], [temos que o número das pessoas livres reduzidas à escravidão é no Brasil nada menos de 700.000.] [construção condicionada] (18:Patrocínio:Campanha - CdP).

Segundo Dancygier (1998), a construção condicionante pode ser introduzida por uma grande variedade de conectores, além do prototípico "se", herdado do latim. Na ocorrência acima, por exemplo, é possível observar duas construções, uma condicionante, introduzida pelo conector "supondo que", e uma condicionada. "Supondo que", conforme Oliveira (2019b), é usado na expressão do sentido condicional.

Neves (2000) e Oliveira (2019b) defendem que os conectores a seguir conseguem, de alguma maneira, atuar na construção do sentido condicional: "desde que", "somente se", "exceto se", "contanto que", "ao menos que", "a não ser que", "dado que", "posto que", "considerando que", "na condição de que", entre outros.

Como se pode perceber, a categoria dos conectores condicionais apresenta um número alto de frequência type, formados a partir da combinação de construções de classes gramaticais distintas juntamente com as construções "que" ou "se", conforme se pode observar mais claramente a seguir, a rede dos conectores condicionais na língua portuguesa:

Esquema 1. Rede dos conectores condicionais

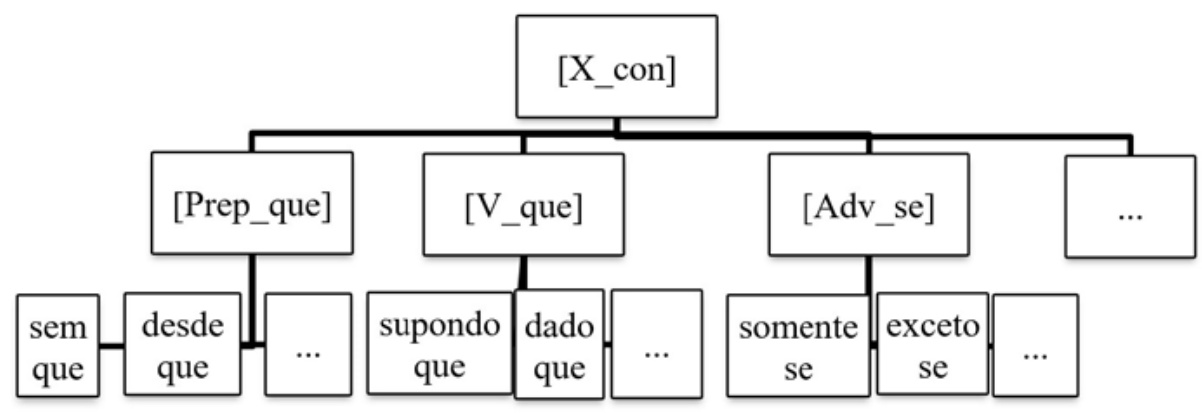

Fonte: Elaboração própria 
Por falta de espaço, acima se vê apenas uma parte da rede dos conectores condicionais. Além de seus vários subesquemas, esses sancionam diversas microconstruções. Como se pode ver, a construção condicional [V_que], objeto de estudo deste trabalho, encontrase no nível de subesquema na rede dos conectores condicionais, assim como [Prep_que], [Adv_se] e outros aqui não mencionados. As construções [supondo que] e [dado que] encontram-se no nível de microconstrução, assim como [considerando que] e [posto que], outras microconstruções do subesquema condicional [V_que]. Logo, no recorte desse trabalho, classifica-se [X_con] como a construção mais esquemática, [V_que] como esquematicamente intermediária e "dado que", "posto que" e "supondo que" são as menos esquemáticas.

Embora os conectores sejam de grande importância para a construção do sentido condicional, Dancygier (1998) e Dancygier e Sweeteser (2005) propõem alguns critérios para que as condicionais sejam reconhecidas em qualquer idioma. São eles: relação de causalidade, marcas de não assertividade, marcas de postura epistêmica, capacidade de predição e capacidade de criação de espaços mentais.

A interpretação existente entre as construções p e q das condicionais é de causalidade não preenchida. Segundo Oliveira e Hirata-Vale (2017, p. 300): "[...] a relação de causalidade está na base do significado condicional, que se forma a partir da sequencialidade estabelecida entre eventos, proposições e atos de fala". Essa relação pode ser vista claramente nos domínios cognitivos propostos por Sweetser (1990) e Dancygier (1998), que analisa a semântica entre p e q nas construções condicionais. São eles: de conteúdo, de atos de fala, epistêmico e metatextual.

As condicionais de conteúdo apresentam uma relação mais perceptível de causa relação, como dependência na realização dos estados-de-coisas. Nas condicionais epistêmicas também é possível visualizar certa relação de causa entre p e q, embora em menor teor do que as de conteúdo, uma vez que a construção pode ser interpretada como a verdade de $\mathrm{p}$ acarreta a verdade de $\mathrm{q}$. As condicionais de atos de fala são altamente intersubjetivas, pois o evento de fala é construído sobre a atitude do locutor perante o ouvinte, sem relação entre p e q. O usuário da língua apenas acredita que a informação da p seja relevante para enunciar q. Por fim, o tipo mais abstrato e intersubjetivo, o domínio metatextual, que se caracteriza por fazer referência a algum elemento do momento da interação, ou seja, há uma retomada de algo dito anteriormente no discurso.

Isto posto, vê-se que as construções condicionais podem associar-se em diferentes domínios cognitivos. Tal gradiência relaciona-se com a leitura semântico-pragmática existente entre p e q: é nos domínios de conteúdo e epistêmico que mais está presente a relação causal, enquanto os domínios de ato de fala e metatextual são mais dependentes do discurso, com menor interpretação de causa. 
A não assertividade é o traço básico presente em todas as condicionais, uma vez que toda construção condicional apresenta suposições, que podem ser consideradas, mas não podem ser tidas como reais. Sendo assim, toda construção condicional caracterizase por seu conteúdo não factual. A não assertividade das construções é marcada pelo uso do conector ou pelos tempos e modos verbais utilizados nas proposições $p$ e q.

Em termos de postura epistêmica, o conector ou os tempos e modos verbais utilizados nas construções condicionais marcam o distanciamento do enunciador perante os fatos enunciados. Nesse sentido, o usuário da língua pode apresentar postura epistêmica neutra, quando não demonstra crença nem descrença, ou postura epistêmica negativa, quando demonstra acreditar na impossibilidade de realização da proposição.

Um quarto critério, a capacidade de predição nas construções condicionais, as construções condicionadas, q, funcionam como uma previsão hipotética futura, ou seja, elas mostram uma situação que poderia acontecer no futuro, caso a condição de p viesse a se realizar. A predição é estabelecida pelos tempos e modos verbais utilizados em $p$ e em q. Geralmente, a proposição q apresenta verbo no futuro em relação à p.

Outro critério relevante é a capacidade de criação de espaços mentais: a partir do uso do conector ou do emprego do tempo e modo verbal, as construções condicionais criam espaços mentais hipotéticos, isto é, situações não reais, que são apenas levadas em consideração no discurso.

O intuito de apresentar os parâmetros da condicionalidade de Dancygier (1998) justifica-se na tentativa de demonstrar que o significado condicional é "simbólico e não composicional" (OLIVEIRA, 2019b, p. 119), ou seja, não é a simples soma do significado das partes ou o significado de apenas um elemento da construção que a classifica como uma construção condicional. Assim, a forma verbal, a escolha do conector, entre outros aspectos, em conjunto, instauram sua leitura condicional.

Consoante, Oliveira (2019b) afirma que não é possível apenas considerar o conector como o fundador do sentido condicional, uma vez que há conectores que veiculam factualidade e não conseguem, por si só, instaurar o sentido condicional, como os casos de "desde que", "dado que", "posto que", entre outros. O sentido condicional das construções compostas desses conectores emerge da correlação de vários fatores envolvidos na construção. Vejam os exemplos (5-7):

5. Desde que a informação seja fornecida, permanece lá para toda a vida (OLIVEIRA, 2008, p. 82). 
6. Escolhido este caminho não se cogitou de o transformar em linha de operações, pela escolha de dois ou três pontos defensáveis, garantidos de guarnições que, mesmo diminutas, pudessem estear a resistência, dado que houvesse um insucesso, um recuo ou uma retirada. (19:Fic:Br:Cunha:Sertoes - CdP).

7. Assim acontecera a S. Diogo, que estuprara uma donzela e, saciada a fome bestial, lançara o corpo a um rio. E, posto que aquele grande criminoso fosse beatificado e da vítima nem se soubesse o nome, grande mercê seria para todo o cristão ser-lhe poupado tal cálice. (19:Fic:Pt:Ribeiro:Avia - CdP).

Nas ocorrências de (5) a (7), os conectores vinculam factualidade e não conseguem estabelecer o significado condicional, que, então, emerge da correlação de vários elementos das construções, como o tempo e modo verbais. De (5) a (7), observa-se o uso do subjuntivo, respectivamente em "seja", "houvesse" e "fosse". São eles que marcam não factualidade e ajudam a tornar os enunciados não assertivos. Diferentemente de conectores como "supondo que", marcador de não assertividade. Vejam o exemplo (8):

8. Comentário adicionado a posteriori: Supondo que o produto que eles modificaram foi distribuído sob a GPL (www.gnu.org), eles não estão errados ao esconder as modificações porque a GPL não obriga que as modificações sejam redistribuídas. (190r:Br:Intrv:Web CdP)

Em (8), toda a informação escopada por "supondo que" apresenta leitura hipotética. Conforme Hirata-Vale (2012, p. 395), "como se o falante pedisse ao seu ouvinte que imaginasse tudo o que disse na oração matriz levando em conta sua suposição". Para perceber mais facilmente o papel do conector na construção do sentido condicional, veja a ocorrência (9) sem o uso do conector "supondo que": "o produto que eles modificaram foi distribuído sob a GPL (www.gnu.org)" (190r:Br:Intrv:Web). Sem uso do "supondo que", falta o traço condicional básico, a não assertividade.

Apoiada aos critérios da condicionalidade propostos por Dancygier (1998), Oliveira (2019a, p. 375) afırma que "quanto mais convencional for o significado de uma construção, mais próximo da zona da condicionalidade ela estará. Por outro lado, quanto mais o significado depender de aspectos contextuais, mais periférica e distante do núcleo prototípico será a construção".

Dessa forma, pode-se afirmar que há graus de pertencimento dos membros em relação às categorias linguísticas das quais fazem parte. Alguns membros têm mais características do grupo do que outros membros. "Dado que" e "posto que", por exemplo, apresentam menos características condicionais, e, portanto, encontram-se mais à periferia da condicionalidade; enquanto "supondo que" apresenta mais características condicionais e se encontra mais próximo ao elemento central da categoria, representado por "se". 
Após essas considerações, apresentam-se informações referentes à metodologia utilizada para a realização dessa pesquisa.

\section{Metodologia}

Os dados foram coletados de dois corpora: Corpus do Português e BIT- Prohpor. O Corpus do Português $(C d P)$ é um banco de dados gratuito e on-line (disponível em www.corpusdoportugues.org), composto por mais de 45 milhões de palavras do século XIV ao XX nas modalidades oral e escrita do português europeu e brasileiro. O BIT-Prohpor (disponível em https://www.prohpor.org/bit-banco-textos) é um banco de dados on-line e gratuito, composto por textos escritos do português do século XII ao XX, criado em 2002 por pesquisadores da UFBA. No geral, a decisão de busca em banco de dados da língua se justifica pela necessidade da teoria de trabalhar com dados de língua em uso.

Mais especificamente, o CdP foi escolhido como corpus de análise devido à alta frequência de dados e à facilidade de busca que esse apresenta. Pela plataforma do $C d P$, é possível realizar pesquisas on-line e verificar a frequência total dos textos com a palavra buscada. Entretanto, seus dados iniciam apenas no século XIV.

Para realizar uma busca em séculos anteriores a XIV, escolheu-se o BIT-Prohpor, que embora apresente alguns problemas como falta de textos ou textos de difíceis leituras (por serem muito antigos e terem sido digitalizados), ele permite uma busca em uma grande variedade de textos: textos em prosa literária (traduções e na língua vernácula), poesia, prosa epistolar e textos notariais/foros. Além disso, o BIT- Prohpor direciona a pesquisa para o Corpus Histórico do Português TychoBrahe, da Universidade Estadual de Campinas (UNICAMP), o que faz com que o pesquisador tenha ainda mais dados para a busca.

No total, foram coletadas 37 ocorrências, entre os séculos XVIII e XX, com as seguintes características: i) ter leitura condicional; ii) ser composto pela combinação verbo + que. Os dados coletados são compostos apenas das microconstruções "dado que", "posto que" e "supondo que", pois esses são os primeiros membros do subesquema [V_que] com sentido condicional. Ou seja, são eles os fundadores desse subesquema.

Após a coleta, realizou-se a análise de dados, com base na teoria da mudança linguística de Traugott e Trousdale (2013), a fim de verificar as mudanças que fizeram emergir o subesquema [V_que] na rede dos conectores condicionais no português, e com os parâmetros da condicionalidade de Dancygier (1998), para analisar o grau de pertencimento das microconstruções do subesquema [V_que] a categoria condicional. Para a definição do sentido condicional, assentou-se principalmente em Dancygier (1998) e Oliveira (2019a, 2019b). 


\section{Análise dos dados}

Os dados coletados mostram que o type mais antigo é "supondo que", com duas ocorrências como conector condicional já no século XVIII. Veja:

Tabela 1. Frequências type e token do subesquema condicional [V_que] por século

\begin{tabular}{cc|c|c|c}
\hline & & Século XVIII & Século XIX & Século XX \\
\hline [supondo que] & condição & 2 & 7 & 13 \\
\hline [dado que] & condição & 0 & 5 & 3 \\
\hline [posto que] & condição & 0 & 4 & 3 \\
\hline \multicolumn{2}{c|}{ Total: } & 2 & 16 & 19 \\
\hline
\end{tabular}

Fonte: Elaboração própria

Considerando os micropassos de mudanças propostos por Traugott e Trousdale (2013), o primeiro passo a caminho da construcionalização foi os dois usos inovadores de "supondo que", no século XVIII, como mostrado na tabela acima. De acordo com Oliveira (2019a, p. 380), o "significado condicional em 'supondo que' é resultado de uma série de micromudanças de forma e de significado que levam à abstratização do significado lexical do verbo base do conectivo".

Mais detalhadamente, o ponto de partida para a formação do conector condicional "supondo que" é o significado de sua base verbal, já que "supor" é "pensar hipoteticamente em algo" e se expande para um domínio mais modal no século XVII, com a forma "supondo que", até que começa a escopar construções hipotéticas, mas, conforme entende HirataVale (2012), nesse momento, ele ainda não funciona como conector condicional. Já no século XVIII, não há mais um sujeito gramatical que concorde com o verbo "supondo", uma vez que o usuário da língua utiliza "supondo que" para marcar sua própria atitude, como se vê na ocorrência (9). Há, então, uma expansão do significado original do núcleo de "supondo que" e esse passa a marcar não factualidade da construção, funcionando como conector condicional:

9. Em lugar de Horácio, nestes princípios, aconselharia Catulo, que é não só puríssimo Latinista, mas mui natural e com infinitas graças. Devem-se separar os poemas impúdicos, e explicar os outros com todo o cuidado e diligência. Mas, supondo que o Mestre não tem os ditos livros, direi o que deve fazer depois da leitura de Fedro e Terêncio. (Verney, L. A. (1713): Verdadeiro Método de Estudar - BIT Prohpor).

Conforme Bueno (2015), "supondo que" com baixa frequência é utilizado apenas em contextos específicos, em textos ficcionais, como na ocorrência (9) acima. Só no século XIX há sua convencionalização e construcionalização, com o aumento da frequência 
token, que mais que triplicou (de duas ocorrências para sete), conforme mostra a tabela (1). Assim, o conector passa a ser usado em outros contextos discursivos.

A construcionalização do conector "supondo que" ativou a entrada de outros membros, "dado que" e "posto que", advindos do subesquema [V_que] da rede causal, por associação à forma (verbo + que). Nesse percurso, o subesquema causal [V_que] passou por neoanálise de traços semânticos, via extensão metafórica do campo da causalidade preenchida (conector causal) para a causalidade não preenchida (conector condicional), atraído pelo membro "supondo que", e assim, fez surgir o subesquema condicional [V_ que], com membros como "dado que", "posto que" e "supondo que".

De acordo com Barreto (1999), "dado que" já inicia no português como conjunção causal no século XVI, e mais tardiamente "posto que", no século XVII, também com valor causal. Apenas no século XIX são utilizados como conectores condicionais, como se observa nas ocorrências (10) e (11), respectivamente.

10. De sorte que, em ali chegando, os invasores seriam inteiramente circulados de balas, E dado que conseguissem avançar, ainda teriam adiante, transcorrido um quilômetro, o aniquilamento inevitável. (18:Cunha:Sertões - CdP).

11. §. 4. A Recapitulação é necessaria na Peroração, e até deve fzer-se parcialmente em outras partes do discurso, como são a Narração, e a Confirmação, quando o discurso é complicado em accidentes, ou quando consta de muitos pontos, ou quando, posto que conste de um só, este é confirmado com muitas provas. Será porêm denecessaria, quando o discurso for simples e breve. (18:Carvalho:Eloquencia_- CdP).

Atualmente, o subesquema [V_que] é membro da rede dos conectores causais e condicionais, sendo seu uso causal o mais prototípico. Observe a figura (1), a seguir:

Figura 1. O subesquema [V_que] na rede linguística

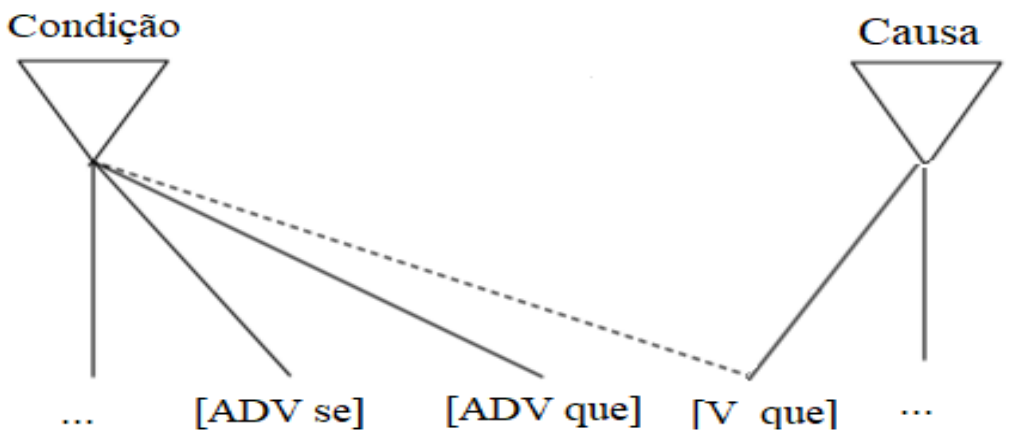

Fonte: Elaboração própria 
Na figura (1) acima, verifica-se que o subesquema [V_que] é membro das categorias causal e condicional. Porém, a linha contínua que o liga à causa indica seu uso mais prototípico, isso é, ele é mais utilizado na língua para a expressão de causa; enquanto os tracejados indicam seu uso menos prototípico, de condição, com poucas ocorrências na língua até o século XX.

Ainda, conforme se nota na tabela (1), observa-se que os dois membros advindos da categoria causa, "dado que" e "posto que", têm uma diminuição de frequência token, enquanto o membro "supondo que" apresenta um grande aumento. Mesmo assim, no geral, a frequência token do subesquema [V_que] condicional se mostra em aumento gradativo, assim como a frequência type. Pode-se afırmar que a microconstrução "supondo que" é o type mais produtivo desse subesquema. Tal fato justifica-se, pois "supondo que" apresenta mais traços condicionais do que os outros membros, que pode ser comprovado a partir da análise com os parâmetros da condicionalidade de Dancygier (1998).

O contexto não assertivo é estabelecido devido ao uso do conectivo, no caso de "supondo que", em (10), ou da configuração verbal, nos casos de "dado que" e "posto que", respectivamente em (11) e (12), com o uso do subjuntivo:

10. Se o semi-diâmetro de uma esfera de a mesma densidade que o Sol em a proporção de quinhentos para um, e supondo que a luz é atraída por a mesma força e proporção a sua massa com outros corpos, toda a luz emitida por esse corpo seria obrigada a retornar contra ele por a sua própria gravidade. (19-04-09 PT - CdP)

11. Não sabia responder isto e até hoje não sei responder, e ainda mais se me perguntava, nesse caso de alcoólico: no ato da geração, dado que fosse a verdade essa sinistra teoria da herança de defeitos e vícios, o pai já seria deveras um alcoólico que tivesse as suas células fecundantes suficientemente modificadas, igualmente, para transmitir a sua desgraça ao filho virtual? (19:Fic:Br:Barreto:Cemitério - CdP)

12. Art. 460. Se for aleatório o contrato, por se referir a coisas existentes, mas expostas a risco, assumido pelo adquirente, terá igualmente direito o alienante a todo o preço, posto que a coisa já não existisse, em parte, ou de todo, no dia do contrato. (19Ac:Br:Lac:Misc $-(d P)$

No tocante à postura epistêmica, "supondo que" consegue marcar o distanciamento do usuário da língua perante a veracidade do enunciado. Veja, a seguir, nas ocorrências de (13) a (15): 
13. Comentário adicionado a posteriori: Supondo que o produto que eles modificaram foi distribuído sob a GPL (www.gnu.org), eles não estão errados ao esconder as modificações porque a GPL_não_obriga_que as modificações sejam re-distribuídas. (190r:Br:Intrv:Web $-\mathrm{CdP})$

14. Art. 460. Se for aleatório o contrato, por se referir a coisas existentes, mas expostas a risco, assumido pelo adquirente, terá igualmente direito o alienante a todo o preço, posto que a coisa já não existisse, em parte, ou de todo, no dia do contrato. (19Ac:Br:Lac:Misc $-\mathrm{CdP})$

15. Dado que os dor-mentes fossem dias e que os dias imediatos fossem os dormentes em sucessão no leito da via férrea, por que não saltar por cima dos dias desagradáveis e olhar-se a si mesmo lá da frente, olhar-se como se fosse outra pessoa, ou mesmo, corajosamente, como se fosse ele mesmo, mas em dias já idos e vividos ou em dormentes já pisados e passados? (19:Fic:Br:Callado:Madona - CdP)

Na ocorrência (13), "supondo que" é uma marca de postura epistêmica negativa do enunciador, pois ele não garante a verdade do enunciado. Já nas ocorrências (14) e (15), a configuração verbal é o que contribui para a marcação da postura epistêmica negativa, decorrente do uso do modo subjuntivo em "existisse" e "fosse". O uso dos conectores "dado que" e "posto que" não consegue fazer com que o usuário da língua se distancie da informação contida na construção, uma vez que esses conectores são assertivos.

Outro parâmetro que mostra a contribuição do conector para o significado condicional é a criação de espaços mentais. Enquanto "supondo que" atua como construtor de espaços mentais hipotéticos, como se pode ver em (16), "dado que" e "posto que" não conseguem exercer essa função. Sendo assim, o tempo e o modo verbais da prótase é que são responsáveis em construir os espaços mentais, conforme se observa em (17) e (18):

16. Se nada acontecer, em 2.003 haverá um déficit de R\$\$7 bilhões na Previdência. A situação vai piorar porque existem inúmeras vantagens adicionais que os funcionários levam quando se aposentam. Mesmo supondo que a reforma da Previdência acabe com todas essas vantagens, ele vai levar, pelo menos, o mesmo reajuste que o ativo tem. É difícil segurar essa despesa. (190r:Br:Intrv:ISP-CdP)

17. Não sabia responder isto e até hoje não sei responder, e ainda mais se me perguntava, nesse caso de alcoólico: no ato da geração, dado que fosse a verdade essa sinistra teoria da herança de defeitos e vícios, o pai já seria deveras um alcoólico que tivesse as suas células fecundantes suficientemente modificadas, igualmente, para transmitir a sua desgraça ao filho virtual? (19:Fic:Br:Barreto:Cemitério- CdP) 
18. Reconheço o queimar da chama antiga, Agnosco veteris vestigia flammae; posto que a visão passou e desapareceu... mas deixou gravada na alma a certeza de que... Posto que seja assim tudo isto, a confidência não passará daqui, minhas senhoras: tanto basta para se saber que estou suficientemente habilitado para cronista da minha história, e a minha história é esta. (18:Garrett:Viagens - CdP)

Em (16), "supondo que" abre dois espaços mentais hipotéticos: "a reforma da Presidência acabar com todas essas vantagens" e "levar ao reajuste que o ativo tem". Situações hipotéticas criadas pelo uso da construção condicional. Em (17) "fosse", na prótase, conjugado no pretérito imperfeito do subjuntivo, abre os espaços mentais hipotéticos: "o pai já seria deveras um alcoólico" e "ser verdade a sinistra teoria", ambos podem ser considerados, mas não tidos como verdades. São apenas situações hipotéticas criadas pelo uso da construção condicional. Em (18), "veja", no presente do subjuntivo, abre os espaços mentais hipotéticos: "ser assim tudo isso" e "a confidência não passará daqui".

Em relação à capacidade de predição, a forma verbal de p e de q é que criam a predição, sendo q um verbo futuro em relação a p. Sendo assim, não há como avaliar o grau de prototipia do conector por esse parâmetro. Mas, com os outros aspectos analisados (capacidade de criação de espaços mentais, postura epistêmica e não assertividade), é possível verificar que "supondo que" contribui mais diretamente para construir o significado condicional da construção do que "dado que" e "posto que".

Além disso, com os parâmetros de condicionalidade de Dancygier (1998), é possível perceber que o subesquema [V_que] condicional é não composicional, pois o significado condicional é instaurado por uma série de elementos da construção e do contexto discursivo, em conjunto, e não apenas pelas somas das partes verbo + que. Ao contrário, já não é possível mais perceber características verbais em $V$. As construções são vistas como um todo, como chunks: "supondo que", "dado que" e "posto que".

Em suma, a emergência do subesquema condicional [ $\left.V_{-} q u e\right]$ ocorre por mudança construcional, uma vez que a forma [V_que] muda sua função de causa para a de condição. Mas, também há construcionalização, uma vez que a combinação verbo + que cria novos nós na rede condicional, como o conector "supondo que".

Mais tardiamente, a partir do século XX, o subesquema condicional [V_que] começa a sancionar mais microconstruções, de base verbal cognitiva, tais como, "considerando que", "imaginando que", entre outras, que ainda necessitam de aprofundamento. 


\section{Considerações finais}

A discussão neste trabalho procurou mostrar, pelo viés da abordagem construcional, a emergência do subesquema [V_que] na rede dos conectores condicionais. Para tanto, foi necessário tratar da emergência dos conectores "supondo que", "dado que" e "posto que", por terem sido eles os responsáveis pela emergência do subesquema [V_que] na rede condicional.

Mais especificamente, os dados analisados apontam que o subesquema condicional [V_que] é fruto de construcionalização e mudanças construcionais. Primeiramente, com o surgimento da microconstrução "supondo que", que sofre construcionalização apenas no século XIX, acompanhado de mudanças das microconstruções "dado que" e "posto que", até então membros do subesquema [V_que] com sentido causal.

Foi verificado, também, que o membro mais próximo do núcleo condicional é o conector "supondo que", sendo ele também o membro mais antigo desse subesquema e mais produtivo do subesquema. "Supondo que" apresenta cada vez mais aumento na produtividade token desde seu surgimento até o século XX, conforme visto na tabela (1). Tal fato contribui para a produtividade token do subesquema [V_que], que aumenta a cada século.

Com base nos resultados discutidos, este trabalho dá uma contribuição adicional para o entendimento da categoria dos conectores na língua portuguesa, em especial, da categoria condicional, que tem se mostrado uma categoria complexa. Espera-se, também, mostrar que as condicionais são construções não composicionais, produtivas e com vários graus de esquematicidade.

\section{REFERÊNCIAS}

BARRETO, T. M. M. Gramaticalização das conjunções na história do português. 1999. Tese (Doutorado em Letras) - Instituto de Letras, Universidade Federal da Bahia, Salvador, 1999.

BUENO, A. F. O conector supondo que no português. 2015. Dissertação (Mestrado em Estudos Linguísticos) - Faculdade de Artes, Letras e Comunicação, Universidade Federal de Mato Grosso do Sul, Três Lagoas, 2015.

CAVAGUTI, A. P.; HIRATA-VALE, F. B. M. A configuração semântica de orações causaiscondicionais no português do Brasil segundo a Gramática Discursivo-Funcional. Veredas, Juiz de Fora, v. 18, p. 101-120, 2014.

CROFT, W. Radical construction grammar. Oxford: Oxford University Press, 2001. 
DANCYGIER, B. Conditionals and predication. Cambridge: Cambridge University Press, 1998.

DANCYGIER, B.; SWEETSER, E. Mental spaces in grammar: conditional constructions. Cambridge: Cambridge University Press, 2005.

HILPERT, M Construction Grammar and its Application to English. Edinburgh: Edinburgh University Press, 2014.

HIRATA-VALE, F. B. M. O conectivo complexo "supondo que": história e uso. In: FIGUEIREDO, D. de C. et al. (org.). Sociedade, cognição e linguagem. Florianópolis: Editora Insular, 2012. p. 381-402.

LANGACKER, R. Foundations of cognitive grammar. v 1. Stanford: Stanford University Press, 1987.

OLIVEIRA, T. P. A construção [[supondo_que]CON. Estudos Linguísticos; São Paulo, v. 48, n. 1, p. 370-83, 2019a.

OLIVEIRA, T. P. A construção condicional em português. Revista de Letras, v. 2, n. 38, 2019b.

OLIVEIRA, T. P. Conjunções e orações condicionais no português do Brasil. 2008. Tese (Doutorado em Linguística e Língua Portuguesa) - Faculdade de Ciências e Letras, Universidade Estadual Paulista "Júlio de Mesquita Filho", Araraquara, 2008.

OLIVEIRA, T. P.; HIRATA-VALE, F. B. M. A condicionalidade como zona conceitual. DELTA, v. 33, n. 1, p. 291-313, 2017.

ROSÁRIO, I. C.; OLIVEIRA, M. R. Funcionalismo e abordagem construcional da gramática. Alfa, São Paulo, v. 60, n. 2, p. 233-259, 2016.

SOARES, B. A construcionalização de 'a gente' no Português Brasileiro: uma abordagem da Linguística Centrada no Uso. Revista Linguística Rio, v. 1, p. 3, 2014.

TRAUGOTT, E. C.; TROUSDALE, G. Constructionalization and Construcional Change. Oxford: Oxford University Press, 2013. 